\title{
Stakeholders Interaction and Social Learning: The case of Push-pull Technology Implementation for Stemborer Pest Control in Ethiopia
}

Isaac Mbeche Nyang'au ${ }^{1,2,}$, Girma Kelboro', Anna-Katharina Hornidge ${ }^{3,4}$, Charles A.O. Midega ${ }^{2}$ and Christian Borgemeister ${ }^{1}$

${ }^{1}$ Center for Development Research (ZEF), University of Bonn, Genscherallee 3, Bonn, Germany; ${ }^{2}$ International Centre of Insect Physiology and Ecology (ICIPE), P.O. Box 30772- 00100, Nairobi, Kenya;

${ }^{3}$ University of Bremen, Institute of Sociology

${ }^{4}$ Leibniz Center for Tropical Marine Research (ZMT), Fahrenheitstr 6, Bremen, Germany

* Correspondence: imbeche@icipe.org; Tel.: +254799615194

\begin{abstract}
Stemborer pests contribute to significant maize crop yield loses incurred by the smallholder famers in Ethiopia. The problem requires requires concerted effort to learn and adopt new innovations to find a long lasting solution. In this study, the on-farm implementation of the push-pull technology (PPT) was used as a platform for interaction and enhancing the social learning among the stakeholders in the maize growing Woredas of Bako Tibe, Jimma Arjo and Yayu in the Oromia region. The main stakeholders were the smallholder maize farmers, researchers and the extension staffs. The study took place between August 2014 to May 2015. The PPT is a biological based strategy addresses the stemborer pest problem in maize crop. Under the strategy, maize crop is intercropped with a stemborer moth repellent fodder legume, Desmodium (the push) together with an attractant trap plant, Napier/Brachiaria grass (the pull) planted around maize-legume intercrop. The study was implemented based on the transdisciplinary action research approach and qualitative data collected during focus group discussions, key informant interviews, stakeholder workshops, participant observations and onfarm PPT demonstrations. The findings show that, the involvement of different stakeholders in joint PPT activities in an interactive environment is an innovation in itself. It creates opportunities for the stakeholders' empowerment as well as deliberating on the contributions from each other to overcome uncertainties about the technology and create new knowledge. The intercropping strategy of maize with Desmodium and Napier/Brachiaria is used to reintroduce the traditional mixed cropping system of smallholder agriculture as strategy for control of pests.
\end{abstract}

Key Words

Push-pull technology, Stemborers, stakeholder interaction, social learning, Ethiopia 


\section{Introduction}

The smallholder maize crop production plays a central role in addressing the food security in Ethiopia. However, stemborer pest infestations contribute to significant maize crop yield loses incurred by the farmers [1]. It is difficult to control these pests, largely as a result of the cryptic and nocturnal habits of the moths, and protection provided by host stem for immature stages [2]. This is a challenge to the researchers, extension service providers and farmers who are the major stakeholders in the sector. At the same time, sustainable growth of the agricultural sector requires the generation and adoption of new technologies and approaches to address its challenges [3]. The stemborer pest is a common problem which requires concerted effort and willingness to learn and act together among the stakeholders in order to find a long lasting solution. This could be achieved through sharing and combining different stakeholders' views, interests, norms, values and knowledge both from the realm of practice and scientific research [4]. The prospects for success of such engagement can be built on the organization of the process and nature of interaction of the participating stakeholders[5].

In this study, the practical on farm and joint stakeholder implementation of the push-pull technology (PPT) was used as a platform for interaction and enhancing the social learning process. Social learning is the collective action and reflection that takes place when different stakeholders work together to improve their human and environmental conditions [6]. That means, affected individuals have to learn together, innovate and adapt as a way of responding to their changing social and environmental needs. However, during the interaction process, the expectations of the different stakeholders are influenced and shaped by their knowledge settings, cultures and interests [7]. Thus, the major point of concern now is how the crossboundary learning processes can be facilitated and made effective in such a situation with diverse viewpoints and expectations among different stakeholders. That means, social learning is not just participation or learning in a group setting. It involves active engagement of different individuals in an interactive and communicative process which ensures that there is mutual understanding of the challenges, conflicts and social dilemmas and creating strategies for improvement $[8,9]$. The interaction processes to enable social learning does not happen automatically. It requires a concerted effort which extends beyond the scope of a single discipline or approach in order to encompass diverse cultures and perspectives[10,11]. This makes social learning in the joint PPT implementation a subject of interest

Innovation and social learning within a social system requires a constant interaction of individuals and organizations possessing different types of knowledge[12,13]. In order to 
achieve this, the different stakeholders have to align their diverse attitudes, motivations and values into a shared pool of knowledge and collective action[14]. The process must also demonstrate that a change in understanding of the complexity of problem at hand such as stemborer pests, has taken place within an individual and become situated within wider society [15]. That means, stakeholder interaction play an important role in social learning from the new relational capacities established between stakeholders, including improved collaboration and a novel understanding of each other's capacities and roles [16-18].

The interaction of the different stakeholders become more learning orientated depending on the way they tackle the problem at hand. In this study, social learning was sought to take place when researchers and other stakeholders shared their knowledge and experiences in a concerted action to address the pressing stemborer pest problem in maize crop using the PPT. On farm joint PPT implementation provided an environment for facilitating learning through sharing and convergence of diverse experiences, interests, knowledge, understanding and expectations of the stakeholders on stemborer pest control. In this article we report on how different stakeholders' viewpoints were shaped based on their research and practice knowledge and experiences and influenced their cross-boundary interaction for social learning and production of new knowledge on stemborer pest control.

\section{The push-pull Technology}

The International Centre of Insect Physiology and Ecology (icipe) and partners during the last two decades have developed the PPT as an innovation that addresses the stemborer pest problem in maize crop. Under the PPT strategy, maize crop is intercropped with a stemborer moth repellent fodder legume, Desmodium (the push), together with an attractant trap plant, Napier/Brachiaria grass (the pull) planted around maize-legume intercrop (Fig. 1). The chemicals produced by Desmodium repel stemborer moths while those produced by the trap grasses attract them[19]. In addition, the trap grasses don't support all stemborer larvae to develop and hence the majority of them die before reaching adulthood [20]. The PPT has additional benefits; suppressing and eliminating Striga weed [21], supporting livestock production through fodder provision, agro-ecosystems resilience through crop intensification and generating income for the smallholder farmers[22]. Currently there are an estimated 150,000 farmers are practicing PPT in East Africa [23]. However, this number of farmers is still low compared to the intensity and magnitude of the stemborer pest problem and the population of smallholder farmers whose livelihood could potentially be improved with the full implementation of PPT. 


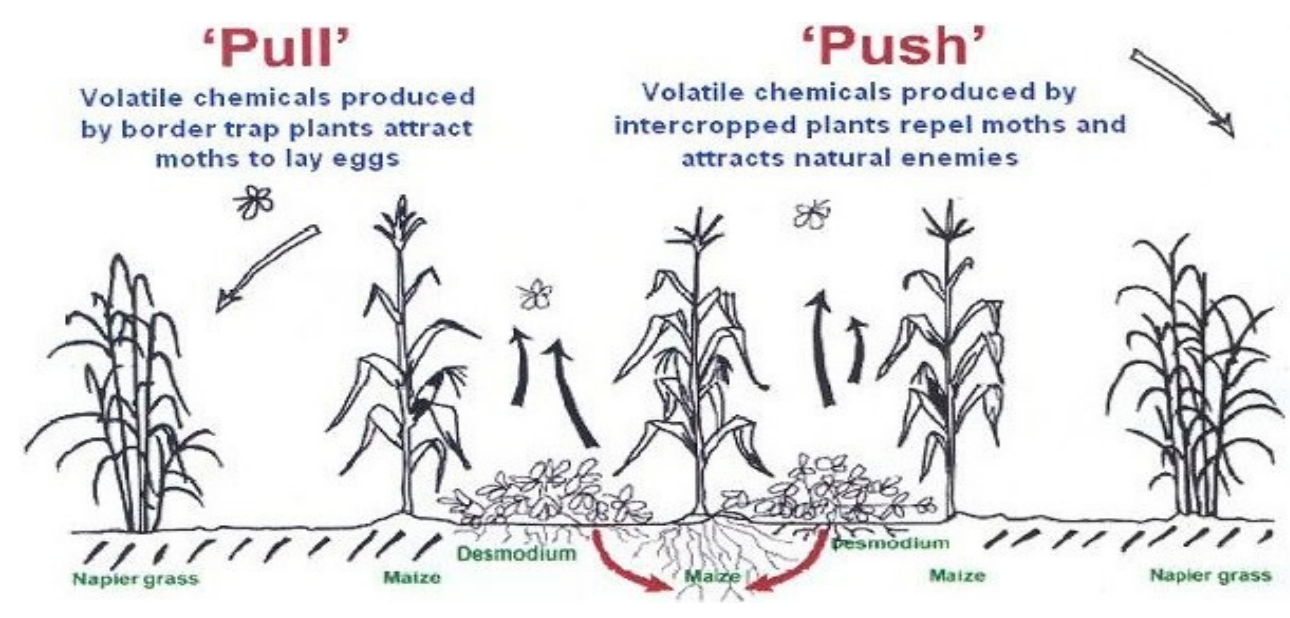

Figure 1: How push-pull technology works.

Source: [24], p.5

\section{Methodology}

\subsection{Transdisciplinary Action Research Process}

The implementation of the study was based on the TDR process $[25,26]$. The TDR is an interactive, collaborative and iterative process which engages different stakeholders in managing systematic enquiries in order to improve their practices and better realize their desired outcomes [27]. It is a participatory paradigm that supports the stakeholders in social learning and knowledge production to address the real-life problems and to develop innovative solutions while incorporating them in new action strategies [25]. The TDR process is systematic and based on PPT implementation stages. The process follows maize crop agronomic and management practices before and after harvesting in the PPT cropping system. This included but not limited to land preparation, planting, weeding, harvesting of either as green maize cobs for roasting or dry cobs for cereals, harvesting Desmodium and Brachiaria grass as fodder for livestock and for seeds. During the off cropping maize season, the PPT activities are mainly on process evaluation of the learning outcomes and impacts.

The study was conducted for a period of 8 months from joint planning and design, to on-farm practical PPT implementation. The researchers and other stakeholders who represented different research disciplines and practice levels came together to jointly address challenge of stemborer pests in maize crop. The scientific research disciplines included; entomology, chemical ecology, weed science, social science where the practice levels interests included the smallholder maize crop farming, extension service provision and farm input marketing. The systematic implementation of PPT was undertaken by the stakeholders as a team and was used as boundary object to enhance TDR process $[28,29]$. The process followed maize crop agronomic 
and management practices spanning from before and after harvesting. This included but not limited to land preparation, planting, weeding, harvesting of either as green maize cobs for roasting or dry cobs for cereals, harvesting Desmodium and Brachiaria grass as fodder for livestock and for seeds.

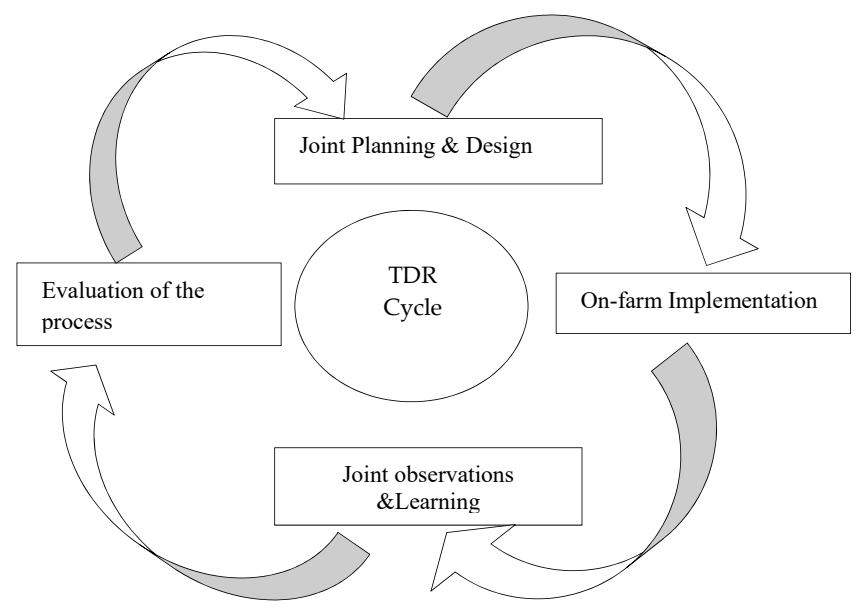

Figure 2: The Transdisciplinary Action Research Cycle

\subsection{Research Design and Data Collection}

The research process started with identification and mobilization of stakeholders. The identified stakeholders were drawn from Ministry of Agriculture (MOA), Jimma University, the Ethiopian Institute for Agricultural Research (EIAR), smallholder maize growing farmers, the Oromia regional government Bureau of Agriculture, Media (Radio and Television) and Nongovernmental Organization (NGO)-Environmental Coffee Forest Forum (ECFF). These stakeholders were either directly affected by the stemborer pest problem, were in influential positions such as policy making or had research interests and practical experiences on the pest related challenges. The identified stakeholders were contacted through visiting and were engaged in discussions on the PPT strategy and the proposed TDR approach. The discussions also included organizing the first joint stakeholders' engagement and team building workshop. During the workshop, the PPT was introduced as an innovation to address the problem of maize stemborers and also an opportunity for interaction and social learning. The selection of the study sites was based on the criteria that; maize production in the area is affected by stemborer pests, the river water for irrigation is accessible and farmers are practicing croplivestock production system (Table 1). The workshop participants were from the Ministry of Agriculture (MOA) from federal level, Oromia region, Zones (Iluababora, East Wolega and 
Jimma) Woredas (Jimma Arjo, Bako Tibe and Yayu) and at Woreda level represented by a, farmers and media. The workshop formed TDR teams which were organized mainly into: researchers (University and research stations), MOA extension staff at the Woreda levels and farmers at the Kebele level.

The Woreda level workshops were a follow-up to the first stakeholders' workshop and involved forming teams tasked to identify other local stakeholders in the Kebeles and discuss the criteria to select model farms to be established as PPT learning sites. The guiding principles for model farm selection were; to have access to or has potential for irrigation, the farm owner willingness to participate, the plot size not less than $30 \mathrm{MX} 30 \mathrm{M}$ and accessible to other farmers in the neighborhood. Other responsibilities of the Woreda teams were to plan and organize training workshops at farmer levels, facilitate the joint PPT implementation activities and set indicators for evaluation learning. The Woreda level stakeholders included line ministries of youth and gender, agriculture, livestock, irrigation and cooperatives, agro-dealers, Kebele level administration and smallholder farmers. In each Woreda two Kebales were selected.

The facilitation during the workshops was interactive. This ensured that the stakeholders' views were addressed and appropriately responded to. At the Kebele level, discussions with TDR team were focused on the PPT implementation and how this can be effectively used to solve challenges of stemborers pests, and as a platform for learning. The PPT learning fields provided an opportunity for the researchers, extension staff and the farmers to interact, experiment and to collaboratively learn from each other throughout the maize cropping cycle. The farmers' practices and researchers' scientific and extension-technical knowledge on pest management were put into perspective, discussed, tested and evaluated. Other topics covered include; soil, water conservation and fodder-livestock production. The whole process was based on the action research cycle (Fig. 2) and embedded on the PPT implementation activities from land preparation and layout, planting the crops (maize, Desmodium and Brachiaria), weeding and managing the PPT plot, harvesting of maize, fodder and seeds, and managing the PPT plot during off-season for the subsequent cropping cycle. Facilitation of the process played a key role in balancing the local practices and scientific aspects of these activities while at the same time allowing full participation and productive interaction of the researchers, farmers and extension staff. The diverse needs, ideas, interpretations were used as opportunities for learning by the farmers and other stakeholders.

The study was implemented and evaluated within the study period and the PPT plots were established during short rainy seasons and supplemented by irrigation using water from the adjacent rivers. This period was short to make complete overview of the learning process. However, the transdisciplinary action research approach enables the stakeholder interaction to 
take place on a continuous basis. Additionally, the implementation of PPT is perennial in nature, meaning that the companion crops still remain in the farm over several cropping seasons, thereby providing the stakeholders opportunities to continue learning even after the study was completed. As opined by [17] such long term interactions over several cropping seasons play an important role in social learning and in enhancing the capacities of the stakeholders either as researchers or practitioners.

Table 1: Location of the push-pull Technology learning sites

\begin{tabular}{llllllll}
\hline Study areas & & & \multicolumn{5}{l}{ The PPT Learning Sites } \\
\hline District & Zone & Village/Kebale & AEZ & Specific site & Altitude & $\begin{array}{l}\text { Longitude } \\
(\mathrm{N})\end{array}$ & $\begin{array}{l}\text { Latitude } \\
(\mathrm{E})\end{array}$ \\
Bako Tibe & West Shawa & Dembi Gobu & Mid-land & Gibe river/Muri & 1660 & $09^{\circ} 09.173^{\prime}$ & $037^{\circ} 02.131^{\prime}$ \\
Bako Tibe & West Shawa & Seden Kite & Mid-land & Leku river & 1648 & $09^{\circ} 05.331^{\prime}$ & $037^{\circ} 09.847^{\prime}$ \\
Yayu & Ilu-Ababora & Jame Shono & High land & Sky-sky & 1904 & $08^{\circ} 21.353^{\prime}$ & $035^{\circ} 36.584^{\prime}$ \\
Yayu & Ilu-Ababora & Jame Shono & High land & Jame-Bone & 1870 & $08^{\circ} 21.351^{\prime}$ & $035^{\circ} 57.736^{\prime}$ \\
\hline
\end{tabular}

\subsection{The Study Area}

The study was implemented in the three Woredas of Oromia Region in Ethiopia (Fig. 3). They were identified as the potential maize growing basket by the BiomassWeb project ${ }^{1}$. Traditionally farmers from areas practice smallholder subsistence agriculture with an average of one hectare of cropland for cultivating staple food such as maize[30]

The productivity of cereal yields in the area is low; the soils are severely degraded and poor in organic matter content. This is due to continuous mono-cropping and poor farming practices Insect pests, mainly stemborers are major cereal crop production constraints [31]. The dominant soil types are Nitosols with fertile alluvial soils in valley bottoms and depressions[32]. The major crops are maize, teff, pepper, sorghum, millet and coffee.

$1_{\text {http://www.zef.de/2141.html }}$ 


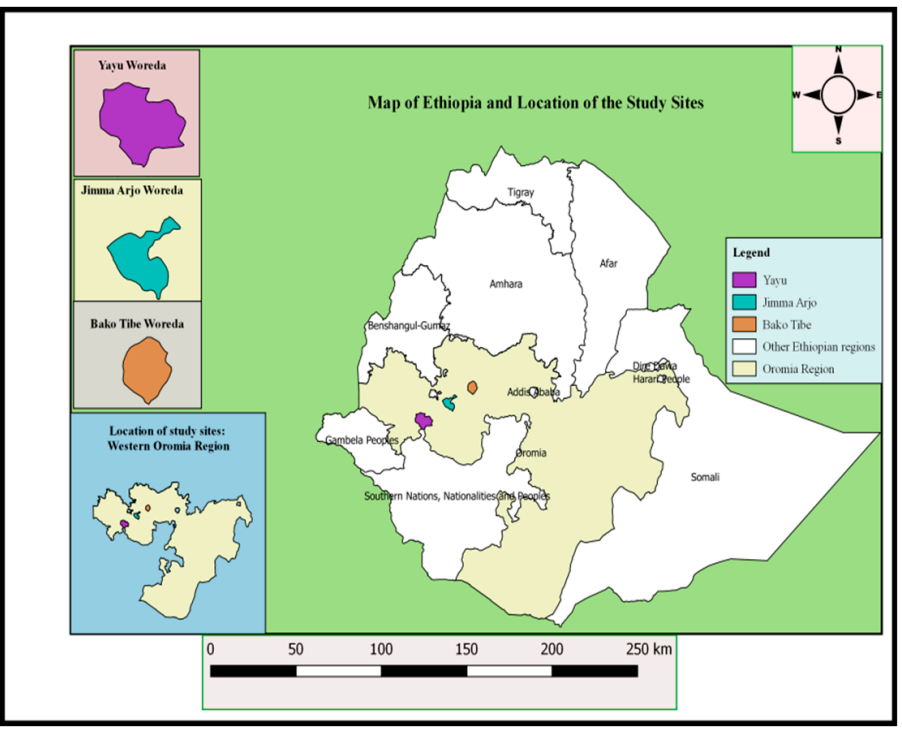

Figure 3: Map of the Study Area.

\subsection{Data Collection and Analysis}

Data collection involved the use of qualitative methods. The process engaged 37 key informant interviews, 16 Focus Group Discussions (FGD), 2 stakeholders' workshops, on-farm practical demonstrations and participant observations. Key informant interviewees were researchers, extension and administration officers from the ministry of Agriculture and farmer leaders. Focus group discussions participants were the PPT farmers and their fellow farmers, development agents and Kebale administrators. The participant observations were based researcher's documentation of the process during stakeholder engagement workshops and onfarm practical demonstration and implementation of the PPT.

The discussions, interviews and observations focused on the different stakeholders' understanding, knowledge, experiences and analysis on stemborer pest's problem in terms of; its effect on cereal yields, type of control measures they were applying, the effectiveness and alternative control measures applied. It also covered on the PPT as an alternative strategy and its on-farm implementation. The new practices learnt during stakeholder interaction but not limited to, PPT implementation process. How collaboration and commitments by different stakeholders can put into use the existing and generate new knowledge in stemborer pest control. The generated data was manually transcribed into themes which were analyzed and interpreted in relation with the research objective. The analysis was guided by the innovation system approach [33,34], Knorr Cetina theory on epistemic cultures[7] and Mollinga theory on boundary crossing [10]. The analysis explores how different stakeholders collaborate and work 
together not only during new technology implementation and learning, but also in generating new knowledge to address the problem of stemborer pests.

\section{The Study Findings}

\subsection{Following the Technology from Doubts to Appreciation}

The introduction of PPT into the study area was meant to address the perennial problem of stemborer pest in maize and other cereal crops. In order to learn about how it works or and as an alternative to previous pest control measures, joint stakeholder interaction was used to illustrate during on farm implementation. This was also a basis for the negotiation and to foster links between researchers and other stakeholders who have interest in the research and maize crop productivity and other related enterprises such as input distribution and marketing. These stakeholders had different knowledge bases, practices and interests emanating from the realm of their research and practice portfolios. Altogether, their interest on learning about PPT as an innovation was inclusive from its historical development, the implementation to evaluation of its performance. Therefore, bringing such diverse groups of different stakeholders to start working and indeed learn together, require boundary works where such heterogeneity is acknowledged and appreciated [10,11].

From the example of Tisenkopfs et al., who looked at how boundary work takes place in a network of farmers' organizations, researchers and extension systems, they found out that:

"boundary work and boundary objects can be used to illustrate how the process of learning takes place from the situation of unfamiliarity and lack of awareness and meaning to increased joint knowledge through intensive negotiation of meaning to gradually arriving at a similar level of familiarity, agreed definition of what the object means and how to deal with it"( [14], p.21).

In this study, PPT was used as a boundary object and a shared practice for the stakeholders to learn and at the same time to address the challenge of stemborers pests in maize crop. During practical implementation process, the stakeholders had the opportunity to learn about and follow its activities and performance along maize crop growth phenology. Like any other new technology, being introduced for the first time, there were mixed expectations and feelings during the initial stages of the implementation. Some of the stakeholders had high expectations on its performance while others were doubtful of its effectiveness. Nevertheless, the interest to learn more about PPT and the stemborer problem at hand kept them motivated from planning to implementation stages: 


\begin{abstract}
“Initially I accepted PPT theoretically without seeing it practically. This was because of the challenges we are faced with from stemborers and wanted to learn more about the technology. I now understand its strategy and other benefits for the farmers from soil fertility improvement, stemborer control to providing additional fodder for livestock......also the intercropping component of the technology, which we have been struggling to educate our farmers about, is now being introduced easily and simply by following the PPT" (KI interview, extension expert, Bako, April 2015).
\end{abstract}

The Ministry of Agriculture's extension office in the study area is faced with resistance from the farmers on the practice of intercropping maize with an additional crop. Intercropping is supposed to act as a strategy for increasing productivity per unit area, stabilize yields and also to provide a good soil cover. However, this has not been easily accepted by the farmers. Conservation agriculture introduced by SG-2000 project [35] reported similar experiences of difficulty for farmers accepting intercropping maize with other crops such as legumes. They regard the practice as an outdated and primitive farming method. Partly this this was attributed to weeding challenges which are associated with intercropping and the nature of extension advice they received previously which laid emphasis on monoculture cropping. For example, some farmers prefer to use an oxen drawn plough to weed their maize fields. Therefore, intercropping maize with another crop will make the ox-ploughing impossible and the same time, hand weeding is labor intensive and expensive when the family has labor shortage. The introduction of PPT was seen as an opportunity to re-introduce intercropping and hand weeding in maize farming. In addition to improving their knowledge on the concept of intercropping maize using Desmodium legume for stemborer control, it was also seen as an extension message package.

\title{
3.2 Uncertainty of the Push-pull Technology
}

Some of the farmers, local extension personnel and researchers were uncertain about the rationale and sustainability the PPT right from the initial stages of the implementation process. The reasons were linked with the unfamiliarity with the technology, fear of being required to incur expenses, commit their already constrained resources such as labor, land or incomes to changing of their traditional farming methods and practices. In addition, they had reservations on the effective performance and unforeseen consequences. According to [36], developer or promoter of a new product such as PPT must anticipate to face such challenges from either at institutional or individual levels of its targeted beneficiaries. The PPT is knowledge intensive based innovation [37] and was newly introduced in the study area. Therefore correct information exchange and right operational environment was crucial for its appreciation. To bring this to fruition, it required learning on a step by step basis in order to clear any doubts 
which may arise or become associated with it. For this reason, the farmers together with researchers and extension staff adopted a step by step learning-based strategy in order to improve the chances of appreciation and clear any fears or uncertainty in the process of following the technology through its activity stages. This strategy was adopted based on the previous experiences where technologies were introduced and a few farmers benefited and other were left out due to lack of awareness or some farmers tending to have a wait and see attitude due to fears or uncertainty:

“Starting with SG 2000, many farmers rejected new technologies, because they lacked full awareness. From that time, I learnt a lot about taking up and accepting new technologies [...] and the benefits it brings to the farmers. Those farmers who took up the new technologies benefited a lot. I expect this technology to be a success for me now and in the future [...]. I think I will gain more by practicing it on my farm" (PPT farmer, Bako Tibe, March 2015).

This particular farmer was able to recall and remember how some farmers benefited from learning and implementing new cropping technologies which were previously introduced by researchers and extension in their area. However, most farmers failed to implement these new technologies due what they felt was related to uncertainties from lack of enough information or to fear of failure. Such experiences were also linked with previous approaches, where the researchers introduced new technologies as on-farm experimental trials. The farmers treated them as such and only serving the researchers' interests. These approaches required that farmers compare their own local practices with the experimental trials. Conducting these trials, over time, it created a sense of loss among the farmers. This was because of the perceived loss of land or space to the long term experimental trials. The experimental yields were certainly better while the control plot or usual practice was poor; hence, the farmer lost an opportunity to have good harvest from the 'so called control plots'. They wished the whole farm was under new crop variety and not under experimentation. However, the set-up of the experiment approach requires that, the control and experimental plots had to be established side by side. The farmers were interested with results of better yields and not observable differences in performances under different treatments i.e. on control and experimental plots. In such instances, the farmers already had information on their plot's previous performance in term of yields. Such procedures of experimentation were associated with some of the farmers becoming averse with new technologies introduced to their area when they didn't see the need for certain implementation steps to be performed. 
One notable example was a brother to PPT farmer who wanted the researchers and extension farmers to help him establish the PPT plot first before he could go ahead and appreciate technology. This particular farmer had a perception that, the PPT was benefiting the researchers and extension staff first and his benefits if any will come much later. Nevertheless, the extension staff together with other farmers assisted him establish the plot, but he never attended to it afterwards. The Desmodium and Brachiaria grass were chocked by weeds. When he was asked why he ignored to maintain the PPT companion crops, he said:

\begin{abstract}
"The researchers and extension never showed interest in my plot after establishment as they did to my brother plot......I lost hope in it. I felt they were not interested to what I was doing in my farm" (Follower farmer interview, Bako Tibe, March 2015).
\end{abstract}

This shows that PPT establishment faces uncertainty especially if it falls on the hand of the farmers who are interested on immediate benefits or those who see and treat it like any other technologies which have been introduced in the past. The introduction of PPT in the farmers' fields was not only meant to address the problem of stemborer pests, but also used as a demonstration sites for joint learning. It was made clear from the beginning that, it was not a trial site to test the new companion crops (Brachiaria grass and Desmodium) or conduct survey interviews to assess farmers' perceptions on effectiveness of PPT. This was made deliberate to avoid repeating the incidents as reported by the farmers where new projects introduce technologies by using farmers' plots for on-farm trials and experimentation to generate data for publications in scientific journals. A notable and practical example cited was the introduction of bulking plots for Napier grass around the study site in Sedan Kite village of Bako Woreda. After the researchers experiment ended, the sites were abandoned and currently overgrown with the Napier grass. There were no follow up made on the next steps in terms of upscaling and training farmers to make use of the abundant seeds for Napier grass propagation. The farmers so far don't know what to do with the Napier grass.

Despite the efforts made, during the introduction of PPT to overcome this, there were mixed results. Some farmers deliberately declined to participate in the technology while other took the technology just to see what 'goodies' may be associated with it:

“The PPT is a good, so far, I have received many visitors interested to see my farm and what am doing with the new technology [...]. However, its management requirements such as hand weeding are too demanding. Am a widow and my children are young. I cannot afford extra labor to pay for the 
weeding [...]. I may not be able to continue with PPT during the subsequent seasons.... (PPT female farmer, comment during field visit, Sedan kite, Bako, April, 2015)

This type of farmer, like others, decided to participate at the start but later realized that, the technology requires commitments and even investment in terms of labor and time during its establishment and maintenance. The choice and selection of farmers to initiate knowledge and labor intensive innovations such the PPT can turn out to be tricky at the beginning of implementation. It requires farmers who are ready to some extend volunteer and also hanger their operations with risk taking in view of long term objectives or gains.

\subsection{Appreciation of the Push-pull Technology}

Despite the doubts, fears and uncertainty expressed, not all farmers and other stakeholders were of pessimistic on the PPT. There were those who started without doubts, dispelled rumors and developed confidence and even started conducting own research activities or making observations and looking for other potential benefits or applications with the PPT. Among the farmers, this group is mostly regarded as the innovators or early adopters. As opined by [38] these farmers know that a new innovation such as PPT has potential to benefit them and gain higher returns if they invest faster. The gains made are both on the short term and long term aspects:

“During the first cropping season under the PPT, we made an observation and noticed that stemborer and birds which are perennial problems had started dropping at significant rate. However, for certainty, we decided to continue to follow these observations for some time during the next subsequent seasons. ...i.e. after 2-3 years, we shall have an overall data and observations to conclude and or make recommendations" (Follower farmer comment during FGD, Bako Tibe, April 2015).

The on-farm joint stakeholders PPT implementation showed that new knowledge can be generated faster and as compared to the traditional research cycle. This was shown with the discussion and comments made by the Bako researchers:

"We have researched for many years and in many places within Oromia region of Ethiopia. Still up to now, we are conducting research to find a permanent solution to stemborer problem. Now, with PPT and within a short period of time, it has been shown that is possible to control stemborers with additional 3 advantages: income, fodder and soil fertility [...]. I suspected the PPT initially because I had my own thoughts as a 
researcher [...]. I have now started to change that position. I have seen practical benefits on the ground. PPT took a short period of time to address a perennial stemborer problem with other additional benefits.... Laboratory based research combined with field and on-farm trials takes over 7 years and not assured of finding a lasting solution to the stemborer problem. This is linked to many factors such as the pests developing resistance, variability of climatic conditions or sometimes farmers not interested with new crop varieties or approaches.... PPT provides a short-cut to this process and indeed an opportunity for other scientists and stakeholders to start learning and be engaged in its implementation" (Interview, Researcher, Bako research center, February and March 2015, Bako Research Center).

According with the Bako researcher, host resistant (maize) research takes a long time. To develop the host resistance, it involves parent crossing and adaptation to different Agroecologies. The procedure for breeding for durable host resistance takes such a long time and farmers can't wait for these results. "Two years ago, Bako center received two maize varieties from Kiboko, Kenya for stemborer resistance research [...], these varieties are still under varietal verification committee. The process has not even started". According to the researchers, the collaboration and team learning, using the example of PPT is a short cut to the whole breeding process, where farmers and scientists come together and agree what is working and it's implemented basing on their needs and real-life-time conditions.

Apart from the problem of stemborer, the maize growing farmers are constantly faced with other challenges such as soil erosion and lack of alternative sources of additional fodder for their livestock. Basing on the potential of the PPT, some of the farmers had interest and actively participated in its implementation:

"From the very beginning when I heard about the technology, I accepted to participate without any doubts.....this was because during the rainy season, I have suffered for many years due to soil erosion. I accepted to use PPT as a measure to prevent soil erosion in addition to stemborer control.... I felt happy to accept the technology to start on my farmland. However, initially the germination of maize was a problem and they looked yellowish and emaciated; gradually the maize growth improved with vigor. According to what I have learnt, this is attributed to the Desmodium and also the quality of the maize seed supplied from Bako Research Center.... At the same time, I haven't seen a lot of stemborers this time round in my maize crops. This is contrary to the normal cropping season, the stemborers infestation is high and there are many birds attacking the maize crop....I hope this Desmodium protects maize from stemborers and 
from Birds!.... I think birds are searching for stemborer eggs on the maize tassel, hence breaking it. I will verify these results on my own.... In this area, horticulture farming especially tomatoes is very challenging mainly due to pests and diseases. I also hope that Desmodium can do the same job on tomatoes? I would like also to find out this fact by my own.... I just want you to provide me with Desmodium seeds and I will provide you with results of my own research after 3 months" (PPT Farmer comment FGD, Bako Tibe, April 2015).

A farmer who takes lead as innovator becomes an example for the rest simply by the fact that he or she is more open to adaptation than fellow farmers. Apart from seeing the potential benefits as prescribed by the promoters of the technology, they seek for other hidden or additional benefits or opportunities. For example, this particular farmer, decided to engage in research by own initiative and made own intuition that birds attack maize cobs while searching for stemborer larvae on maize tassel. This observation and line of thought is completely outside what was initially thought by the researchers or promoters of the PPT. However, the joint implementation of PPT was "participatory and gave the participants" space for learning and to conduct own observations and experimentation guided by their needs and perceptions of the technology. According to this farmer, the priority problem at hand was soil and water conservation, not stemborer as such. This is what initially attracted him to participate in the PPT. In some instances, some of the farmers saw the PPT as an opportunity to produce fodder for livestock while others considered it as opportunity to learn how to control pests in horticultural crops. This is an indication that immediate needs vary and is not necessarily the aligned to the common problem affecting other participating stakeholders. The implementation of PPT is a continuous process along the maize cropping seasons from land preparation, planting, harvesting to processing for marketing. This provides an entry for other players with diverse needs, interests and at different stages of crop management and development. The continuous learning during the process ensures that, even if one has developed some doubts, there are subsequent seasons to learn and make decisions or adjustments or sometimes stop using the PPT.

"Initially when we planted maize, it was not good looking ... by then Desmodium was small and had not grown and established well. As time progressed and maize matured and Desmodium covered the soil, everything now changed for the better. The maize was getting greener despite the fact that it was during short rainy season and we depended on irrigating the fields. The Desmodium cover retained lots of moisture during the day and we attributed all the good observations to Desmodium" (PPT farmer, Sedan Kite village, March 2015, Bako Tibe district). 
The different stakeholders who were doubtful at the beginning of the implementation process were linked to either the newness or unfamiliarity of the technology and also had neither heard nor thought about such as performance. However, their opinion changed as time went by. The maize crop performance was convincing and even better when compared to the previous seasons, although it was established using irrigation.

"Initially I was feeling negative to take up this technology from the researchers and extension agents .....but now I don't want to lose the Desmodium...During main season, weeding is normally a challenge as weeds emerge very fast immediately after first weeding. Now with PPT, I think, much of the weeds will be smothered and there will be less weeding as compared when there is no Desmodium in the field. This technology has lots of potentials and is innovative in all respects.... addressing immediate farmer needs of food security and perennial fodder shortage for livestock" (Interview PPT farmer, Jame Shono Village, March 2014, Yayu district).

Based on the study conducted in the context of Khorezm agricultural system in Uzbekistan, [39] found that trust has to be built to become a basis for any form of cooperation, and precondition for the mutual transfer of new knowledge or implementation of new technologies such as the PPT. They found that continuous interactions through frequent meetings; workshops, group work during activity implementation and seminars, become crucial input to the overall process of building the trust. This is applicable not only among the participant stakeholders but also on what they are promoting or standing in for. In the current study, joint planning and on-farm PPT practical implementation provided an example of follow the innovation initiative from planning, plot layout, planting to crop harvesting and processing stages where the farmers and other stakeholders had frequent interactions and worked together. As time went by, the stakeholders started to develop trust and confidence not only with PPT performance, but also its tangible benefits. This was concurred by comments made by the participants in Bako area in Ethiopia, notably:

"We are now eating the maize. ....we managed to follow PPT from soil to the mouth of both human and livestock.....to health of humans and livestock..... It is beneficial for women who tend livestock; they can plant it on small plots and feed livestock" (Comment made by female PPT during on farm visit, Sedan Kite, Bako Tibe district, April, 2015).

The utilization of the PPT products, mainly healthy green maize and fodder is what culminated the confidence and trust on the performance of the technology as the immediate benefits. These 
benefits formed the basis of building the initial trust which was important to get a buy in from especially the farmers. As time went by and with continuous interactions among the farmers, researchers and extension personnel, new insights were emerging not only about the technology benefits and opportunities but also challenges regarding the technology itself and also related to stakeholder collaborations and engagement.

\section{Discussions}

\subsection{Stakeholder Interactions}

The introduction of PPT was a new approach to the study area and tailored to address the problem of stemborer pest infestation on cereal crops with specific focus on maize. The process brought on-board diverse stakeholders who were deemed as right and faced by the stemborer pest problem, interested to interact freely and learn together. At the federal and regional administrative levels of government, they comprised of researchers, professional extension staff from line the ministries of; youth and representatives of women's affairs, water and irrigation, agriculture, livestock and cooperative development. At the Woreda level, the offices of vice administrators in charge of agriculture were the key stakeholders whose mandate is to coordinate the different agricultural and related departments[40]. The jurisdictions are meant overcome the challenges of inter-departmental boundaries, and to facilitate implementation of project activities. During the planning workshops for this study, the Woredas' vice administrators from the respective focal areas showed interest and promised to provide necessary support. They appreciated and embraced the participatory and transdisciplinary action research approach on PPT implementation. The approach was corresponding with their coordination function and approach i.e., bringing together diverse stakeholders to work as a team towards solving a common development problem. In addition, the Woreda administrative (coordination) offices have institutional, administrative and fiscal empowerment. This gives them the flexibility to initiate and collaborate with projects and programs with similar or complementary objectives.

The PPT implementation process was undertaken in an already established framework of coordination under the leadership of the Woreda vice-administrators in charge of agriculture. These administrative officers' always organized regular meetings for follow-up and to address any pressing or emerging issues within the districts and this study benefited from this setup by having frequent interactions and discussions with Woreda level policy makers. 
Most of the Woreda level extension staff from different ministries accepted to voluntarily support and participate in the implementation of PPT. They were keen and became interested on the science rationale and the PPT strategy, and the agro-ecological principles on pest management which exploit crop-insect-environmental interactions to contribute to stemborer pest control. The research implementation team was also supported by voluntary extension staff from the study Woredas. Most of these extension staffs were undertaking summer classes mainly for bachelor degrees in plant and animal sciences or in natural resource management. They found the scientific concept of PPT not only interesting and linked it with their academic study programs, but also in addressing the problem of stemborer challenges facing their farmers. They were keen to learn more about the technology, from researchers and also from farmers' practical applications on-farm fields. All the DAs at the Kebele levels were mandated to participate in PPT implementation activities in in the study area. In addition, some DAs from the neighboring Kebeles participated in PPT activities to learn and apply the knowledge in the course of their day to day work and in their academic persuasion.

The PPT, although science driven, its implementation process took into account of the already existing efforts of local practices and experiences on pests' control. This interaction between science based research and societal practice is an important aspect of the innovation ecology where a technology embraces diverse knowledge cultures and settings. This is a defining feature for sustainability of such systems [41]. This could be either solving the problem or learning from the experiences of their interactions. This concurs with [8], who stated that, innovations do not just consists of adopting technical devices, but also new social and organizational arrangements and relationships which are established among the actors involved. This kind of openness and team work created a learning framework conditions among the diverse stakeholders who would otherwise worked independently or not even aware of existence of the PPT.

The practical implementation of PPT took place at farmers own fields. This created an opportunity which enabled farmer to farmer learning during PPT implementation. The new PPT farmer fields were used as farmer managed learning sites for practical events such as field days. The follower farmers were able to learn and appreciate the practical benefits about the PPT from fellow farmers whom they share a lot of socio-economic and other related similarities $[42,43]$. The active participation and presence of the researchers and extension staff, who were eager to learn and share their knowledge, was an indication of relevance and importance of the technology for the farmers. This gave the farmers confidence to trust and freedom to open up to and 'embrace' the technology. This was happening against the backdrop of previous encounters whereby the farmers were always suspicious of new technologies or interventions. 
For example, during soil and water conservation campaigns which are conducted annually, the farmers thought that they were being 'forced' to participate in the conservation activities. This resulted in low adoption and lack of commitment to maintain the erected structures. This is partly attributed to the top down nature of the communication entrenched in the country's agriculture extension system and is centrally managed with strong political motives [44]. Previously, success rate in technology adoption was low due to limitation of information provided to the farmers, lack of awareness and even, in some cases, to the extension staff [35].

There is need to have a locally embedded extension system approach which is matched to various agro-ecological zones and responding to the needs and demands of the farmers and other stakeholders in these areas[44,45]. However, this is faced with other challenges from, lack of capacity and empowerment of the relevant stakeholders to learn, acquire knowledge and adapt useful technologies, and at the same time no existing platforms for continuous information dissemination, policy and technology uptake [46]. Equally, the organizational cultures, particularly among public sector providers of extension services are hierarchical, averse to change, and persistently focused on linear approach of science [47].

Agricultural education and extension system requires significantly strong linkages with research and other partners such as the private sector investments to meet the country's development objectives [48]. In light of these experiences, the participatory implementation of PPT using the TDR approach created an environment and framework conditions for farmers to learn stepwise, understand and finally be able to make decision on whether to continue or stop using the technology. It is not so much about technology failure that inhibits uptake but failure of the institutions and actors to make the technology and the system to work (ibid.).

\subsection{New Knowledge and Insights from Implementing the Push-pull Technology}

The new knowledge and insights generated is in reference to new actionable knowledge and strategies developed as a result of the stakeholders interactions during planning and implementation of the PPT. This includes farmer innovations meant to address new challenges which came as a result of participating in the PPT. As a result of stakeholder interactions, new ideas and concepts came up out of observations or were learnt for the first time. The stakeholders had not come across such observations nor were aware of this kind of information before. As opined by McLean (2004), PPT implementation process provided framework conditions for a continuous self-transcending through which the participants were able to transcend the boundary of the old self into a new self by acquiring a new context, new view of the world and new knowledge. 
A notable example was from a farmer during on-farm focus group discussion. He observed that, Brachiaria grass looked fleshy, green and well growing despite the dry weather conditions. Why is this? He wanted to know. During the discussion, the researcher from Bako research center replied that, the Brachiaria grass is adapted to drought conditions in such a way that its rooting system is very extensive allowing it to tolerate low rainfall and enables it to have rapid growth after establishment. Its fleshy looking leaves were as a result of its efficient use of dew on the surface of its leaves and, as a result, able to maintain greenness even during the dry season. Apart from being an effective trap plant for stemborer, this also makes it an alternative forage crop. This was the first time farmers and extension officers were witnessing the Brachiaria grass growing on farm. Previously, they knew it but as a wild grass which grows in the forest. They had not thought of domesticating it on farm as a crop.

The PPT soil conservation properties were supported the natural resource management initiatives by the ministry of agriculture. The PPT introduced new companion crops which were supporting soil and water conservation campaigns. This was appreciated by the stakeholders as an addition to the already existing initiatives. "The Desmodium and Brachiaria rooting systems strengthen the soil. Then, during dry season, the soil doesn't crack thereby reducing the exposure to erosion", farmer comment during focus group discussions. The soil cover effect of the Desmodium before and after harvesting maize crop maintains moisture in the soil. These were new experiences for the farmers.

The PPT introduced landscaping and beautification of farmland arrangement. This was an observations made regarding; the inter-row spacing to allow furrow irrigation without the effect of soil erosion and flooding, while at the same time, having a border crop separated from the main crop with a foot path to allow farm management operations. This is what people are used to do in their compound and not on farm. These make farming attractive and the PPT farm a place to visit and learn:

"The maize and Desmodium rows and boundary grasses of the PPT plot beautify the maize field and the land looks neat and unique and it is attractive....." (PPT Farmer during FGD Bako Tibe, March 2015).

The age-old practice of allowing livestock to roam freely after harvesting cereal crops seemed to be getting re- assessment for possible future solution. During rainy season crops are planted in nearly all the farms and farmers have a social responsibility and as an obligation to guard or fence off their crop fields from being destroyed by livestock. At the same time, there is plenty fodder in the communal grazing lands, around the homesteads; the farmers are not challenged with livestock feeding. However, during the dry season, the farmers have the tradition of letting 
their livestock roam freely in search of feed and also make themselves free to travel to markets or visit relatives rather than stay around to guard their livestock. The PPT plot is perennial, so for it to survive during successive seasons, it has to be protected during off-season. Based on this, the farmers were considering the possibility to control roaming livestock during off-cereal cropping season. It will take some time to bring overall change to this. However, the PPT farmers had initiated this by fencing off their farms. That means, in order to institutionalize guarding or protecting the crop fields during dry season from roaming livestock, this requires further discussion among the stakeholders using the experiences of the PPT farmers.

The PPT introduction created new business investment opportunities which did not exist before such as commercial collection or production of Desmodium and Brachiaria seeds. Previously, after harvesting maize, the animals were left to roam freely on the maize fields. Now with PPT, these plots have to be protected. The farmers had learned to use these plots to plant short-time maturing and high quality legumes such as chickpea.

"With PPT farmers have learned the practice of double cropping....when maize is harvested, the moisture retention under PPT plot is used to sow chickpea. There is no gap for the fields to be free and unattended. Chickpea is planted as a security to the plot under PPT. This knowledge is from the training farmers have received from researchers and extension staffs" (Interview with icipe field technician, Tolay district, May 2015).

The coming together of stakeholders and continuous interactions of the team during PPT implementation with diverse expertise and commitments opened up discussion on other potential benefits such as Desmodium seed collection, not only for income but as a forest enterprise for conservation and green maize during off rainy season. In the study area, for example the silver leaf Desmodium was available in plenty in the Yayu forest area and in the hedges along farm boundaries. With the introduction of PPT, the farmers started seed collection for sale to their neighbors and for the emerging market from new farmers elsewhere. In addition, the coming together of stakeholders during PPT enabled them to resolve a conflict which arose from water use and management during irrigation. Horticultural farmers growing crops such as tomatoes, onions and cabbage during the dry season were fighting over access and distribution of water for irrigation with PPT farmers. The horticultural crop producing farmers felt that water should not be diverted for maize production. This degenerated into a conflict. It took the intervention of the research team together with the affected farmers and officials from the Ministry of Water and Irrigation, to have a joint meeting where it was decided for a formal water use agreement. The Ministry officials together with farmers and local administrators facilitated the negotiation with other water users in the affected areas. The agreements covered on the time and amount of water to be used by each farmer participating in 
irrigation activities. The formal document had all the stakeholders appending their signatures. The potential triggers of the water use conflict were openly discussed and resolution mechanisms were well stipulated and agreed. The agreements outlined how to resolve future conflicts arising out of the water uses. The underlying motive of the agreements was based on the fact the water was being used by many people along the river and everyone had right to access and use. The ministry of water and irrigation officials facilitated the agreements and they have the overall responsibility to ensure that all the stakeholders along the riparian, have user rights without compromising the river ecosystems and other users downstream. These formal agreements overruled the informally agreed water use arrangements.

Fodder provision was a major livestock production challenge in the area attributed to reduced grazing lands from increased farmland. The farmers learnt that it was possible to address these challenges through planting fodder for indoor livestock feeding. The practice of cut-and-carry fodder is a way to explore for the future reducing the quantity of livestock and with more attention to quality. Cut-and-carry is potentially an environmental conservation approach which has win-win for farmers and the livestock. Cutting fodder and feed livestock at home or in a fenced area is hectic but more productive for the farmer as compared to allowing them to roam and graze freely in fields where they have less to feed on and, hence become less productive

\subsection{Farmer Innovations to Address New Push-pull Technology Challenges}

The PPT implementation process came up with new opportunities but at the same time brought new share of challenges at farmers' level. Previously, these farmers had not experienced such problem. Despite the challenges, the farmers together with other stakeholders used them as opportunities for learning. During the process, they developed new strategies to deal with the challenges.

\subsubsection{New Pests Attacking Push-pull Crops}

In the study area, it was too early to notice any new pests associated with PPT. However, the emergence of new pest attack was challenge cited by PPT farmers with more than 1 cropping season. For example in Tolay area, farmers noted that, grasshoppers which were not a problem before the PPT had emerged during the rainy season. The farmers observed that Maize, Teff and millet shoots are not attacked by grasshoppers, but does on Brachiaria grass. Further they noticed that Brachiaria grass is susceptible to grasshoppers in black soils than in red soils. Brachiaria also grass grows faster in red soil than in the black cotton soil. They attributed the attack of grasshoppers by their preference to lay eggs in the black cotton to red soils. 
During the discussions, it was revealed that some farmers replanted Brachiaria grass 2-3 times as a result of persistent attack by the grasshopper pests. This affected growth rate. In order to deal with the problem, the farmers, out of their own intuition, discovered that it was preferable to use root splits to establish Brachiaria in black cotton soils not only to manage the grasshopper pests but also for faster sprouting and tillering. This became an example of a local adapted knowledge based on farmers' own experimentation.

The Blister beetles was not common in the area before PPT. They attacked Desmodium at flowering stage (Fig 4). The farmers observed that the problem was severe on mono crop Desmodium. This posed a serious challenge for the production of Desmodium seeds. At the moment, the farmers have no management strategies, but based on the advice of the chemical ecologist and experience from other countries such as Kenya. The solution to the blister beetles is polyculture arrangement of crops such that between the rows of Desmodium. This was agreeable as it was witnessed by the farmers who observed that in their PPT plots, the blister beetles were not attacking the Desmodium flowers. The mechanical destruction of Blister beetles is not effective. The chemical ecologist in the team recommended the use of simple baits as traps which should be easy to use e.g., the use of flowers as color attractants which are laced biological control agent e.g., fungus. There is need to explore further on odor attractants.

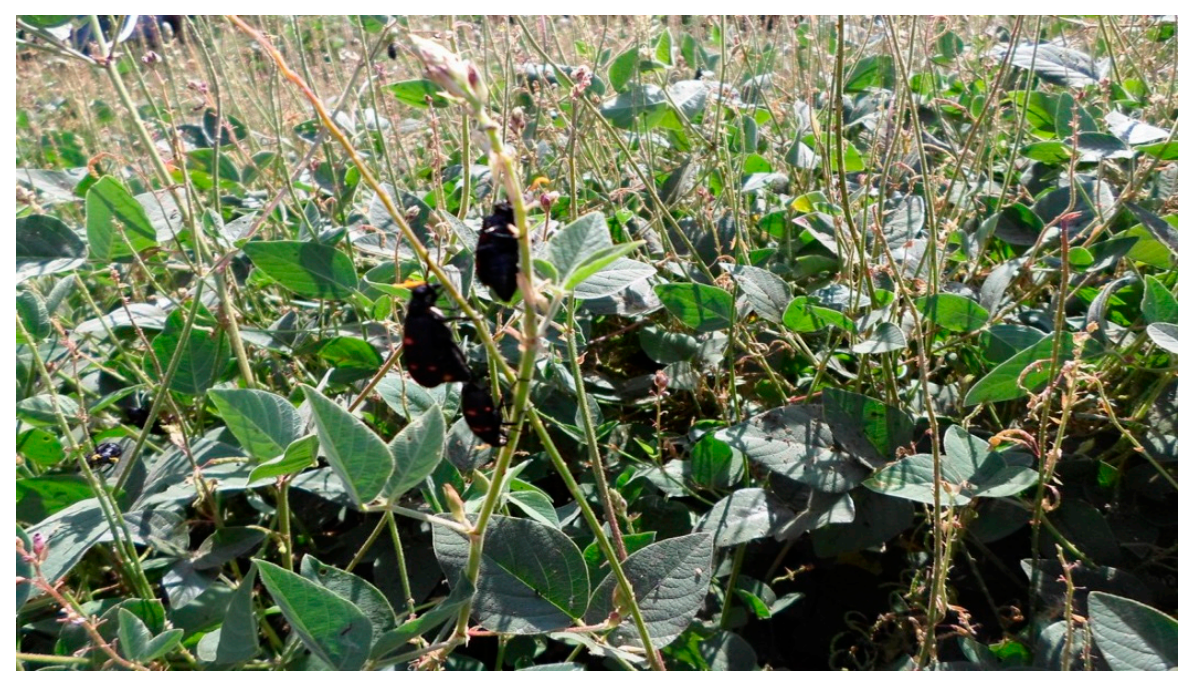

Figure 4: Blister beetles feeding on Desmodium flowers

\subsubsection{Harvesting of Seeds}

The farmers learnt that seeds from Brachiaria and Desmodium can be harvested and used for establishment of the PPT. They required knowing the right timing for harvesting the seeds. When the seeds were mature, they are ready for harvesting; otherwise they dropped to the ground and germinated. This was a loss for the farmers. During the process of stakeholders' 
interactions and field observations, the farmers learnt that Desmodium is harvested after maize has been harvested while Brachiaria is harvested before maize. The PPT companion relative to each other, they mature at different stages. This flexibility enables farmers to effectively pool labor to harvest and manage the crop.

\section{Conclusion}

In conclusion, the findings of the study show that, the involvement of different stakeholders in joint activities and in an interactive environment is an innovation in itself. It creates an opportunity for the stakeholders' empowerment and appreciation and at the same time challenging the contributions from each other. This is different from the top down nature of relationship and communication. The local fit of PPT and its meaningfulness is acknowledged and at the same time its failings or misgivings are openly discussed or revealed. The stakeholders are able open up to solve the real life problem in a participatory and interactive fashion with mutual respect and learn from successes and failures. The presence of career researchers and the senior extension staff during the PPT implementation process is a unique and interesting to the farmers and local extension personnel. At the same time, the existence of a real-life stemborer pest problem which had not yet received any promising solution and PPT as a biological based strategy is a strong motivation for participation.

The use of farmers and their own fields for practical implementation enables critical assessment and relaxed learning about PPT. In such circumstances, the farmers are able to learn and discover the practical benefits of the technology when they see it perform in their own farming conditions. The introduction of the PPT had its share of challenges and situations of negative rumors, fears and doubts especially where the PPT management requires different practices from usual farming practices. Such uncertainties are arising due to lack of enough information and non-effective communication among the stakeholders. The participatory nature of introduction and facilitation plays an important role overcoming such situations where some stakeholders may show unwillingness to implement the technology. This can be used as essential points for learning rather than being sources of contradictions. Also the use of the existing farming practices provides the entry points for easy understanding and relating with the expected changes.

The findings of this study have implications in the nature of PPT dissemination as a conservation farming practice of cover cropping. The PPT is comparable with the practice of allowing weeds to grow in a maize plantation during the later stages of maturity to be used as fodder for livestock or as standing biomass for direct feeding. This practice is an opportunity for the farmers to understand the logic of Desmodium and Brachiaria grass as intercrop and trap 
crops for stemborer pest control, moisture retention and fodder. The intercropping strategy of maize with Desmodium, reintroduces the traditional intercropping system of smallholder agriculture as strategy for the control of pests.

Acknowledgements: The authors highly appreciate the scholarships and financial support received from The German Ministry for Economic Cooperation and Development (BMZ) through the BiomassWeb project (https://biomassweb.org) component of the International Center for Insect Physiology and Ecology (icipe) for the entire study. Special thanks go to the farmers, the Ethiopian Ministry of Agriculture officials, and researchers from the Center for Development research (ZEF), University of Bonn, and the Ethiopian Institute of Agricultural Research (EIAR) who provided guidance and technical support for the study.

Author Contributions: Girma Kelboro and Anna-Katharina Hornidge supported the design of this study, and actively participated in its implementation and provided guidance in data analysis. Midega Charles and Christian Borgemeister contributed with the provision of materials and logistics for field research and data collection; Nyang'au Isaac Mbeche conceived the study, collected and analyzed the data, and, supported by the co-authors, wrote the article.

Conflicts of Interest: No conflict of interest was reported by the authors.

\section{List of tables and figures}

Table 1: Location of the push-pull Technology learning sites

Figure 1: How push-pull technology works. 4

Figure 2: The transdisciplinary Action Research Cycle 5

Figure 3: Map of the Study Area. 8

Figure 4: Blister beetles feeding on Desmodium flowers 


\section{References}

1. Kfir, R.; Overholt, W. A.; Khan, Z. R.; Polaszek, A. BIOLOGY AND MANAGEMENT OF ECONOMICALLY IMPORTANT LEPIDOPTERAN CEREAL STEM BORERS IN AFRICA; 2001;

2. Khan, Z. R.; Midega, C. A. O.; Pittchar, J. O.; Murage, A. W.; Birkett, M. A.; Bruce, T. J. A.; Pickett, J. A. Achieving food security for one million sub-Saharan African poor through push-pull innovation by 2020. Philos. Trans. R. Soc. B Biol. Sci. 2014, 369, 20120284.

3. Stellmacher, T. Local forest governance in Ethiopia: Between legal pluralism and livelihood realities; ZEF Working Paper Series, 2013;

4. Bergman, M.; Coxon, A. The quality in qualitative methods. Forum Qual. Sozialforsch. 2005, doi:10.17169/fqs-6.2.457.

5. Renner, R.; Schneider, F.; Hohenwallner, D.; Kopeinig, C.; Kruse, S.; Lienert, J.; Link, S.; Muhar, S. Meeting the Challenges of Transdisciplinary Knowledge Production for Sustainable Water Governance. Mt. Res. Dev. 2013, 33, 234-247, doi:10.1659/MRDJOURNAL-D-13-00002.1.

6. Brown, V. A.; Keen, M.; Dyball, R. Lessons from the Past, Learning for the Future; 2005; ISBN 1-84407-183-9.

7. Cetina, K. K. Culture in global knowledge societies: knowledge cultures and epistemic cultures. Interdiscip. Sci. Rev. 2007, 32, 361-375, doi:10.1179/030801807X163571.

8. Leeuwis, C. Changing views of agricultural innovation: Implications for communicative intervention and science. Res. to impact case Stud. Nat. Resour. Manag. Irrig. rice Asia 2010, 15.

9. Spielman, D. J.; Ekboir, J.; Davis, K.; Ochieng, C. M. O. An innovation systems perspective on strengthening agricultural education and training in sub-Saharan Africa. Agric. Syst. 2008, 98, 1-9, doi:10.1016/j.agsy.2008.03.004.

10. Mollinga, P. P. Transdisciplinary method for water pollution and human health research; ZEF Working Paper Series, 2010;

11. Akkerman, S. F.; Bakker, A. Boundary Crossing and Boundary Objects. Rev. Educ. Res. 2011, 81, 132-169, doi:10.3102/0034654311404435.

12. Anandajayasekeram, P.; Gebremedhin, B. Integrating innovation systems perspective and value chain analysis in agricultural research for development: Implications and challenges. 2009.

13. Bank, W. Building Science, Technology and Innovation Capacity in Rwanda; The World Bank, 
2008; ISBN 978-0-8213-7356-9 978-0-8213-7357-6.

14. Tisenkopfs, T.; Kunda, I.; šūmane, S.; Brunori, G.; Klerkx, L.; Moschitz, H. Learning and Innovation in Agriculture and Rural Development: The Use of the Concepts of Boundary Work and Boundary Objects. J. Agric. Educ. Ext. 2015, 21, 13-33, doi:10.1080/1389224X.2014.991115.

15. Reed, M.; Evely, A. C.; Cundill, G.; Fazey, I. R. A.; Glass, J.; Laing, A.; Newig, J.; Parrish, B.; Prell, C.; Raymond, C.; others What is social learning? Ecol. Soc. 2010.

16. Pahl-Wostl, C. A conceptual framework for analysing adaptive capacity and multi-level learning processes in resource governance regimes. Glob. Environ. Chang. 2009, 19, 354365, doi:10.1016/j.gloenvcha.2009.06.001.

17. Scholz, G.; Dewulf, A.; Pahl-Wostl, C. An Analytical Framework of Social Learning Facilitated by Participatory Methods. Syst. Pract. Action Res. 2014, 27, 575-591, doi:10.1007/s11213-013-9310-z.

18. Bandura, A. C. N.-L. . B. Social learning theory; Prentice Hall: Englewood Cliffs, N.J, 1977; ISBN 978-0-13-816751-6.

19. Chamberlain, K.; Khan, Z. R.; Pickett, J. A.; Toshova, T.; Wadhams, L. J. Diel periodicity in the production of green leaf volatiles by wild and cultivated host plants of stemborer moths, Chilo partellus and Busseola fusca. J. Chem. Ecol. 2006, 32, 565-577, doi:10.1007/s10886-005-9016-5.

20. Khan, Z. R.; Midega, C. A. O.; Wadhams, L. J.; Pickett, J. A.; Mumuni, A. Evaluation of Napier grass (Pennisetum purpureum) varieties for use as trap plants for the management of African stemborer (Busseola fusca) in a push?pull strategy. Entomol. Exp. Appl. 2007, 124, 201-211, doi:10.1111/j.1570-7458.2007.00569.x.

21. Khan, Z. R.; Pickett, J. A.; Wadhams, L. J.; Hassanali, A.; Midega, C. A. O. Combined control of Striga hermonthica and stemborers by maize-Desmodium spp. intercrops. Crop Prot. 2006, 25, 989-995, doi:10.1016/j.cropro.2006.01.008.

22. Khan, Z. R.; Midega, C. A. O.; Njuguna, E. M.; Amudavi, D. M.; Wanyama, J. M.; Pickett, J. A. Economic performance of the 'push-pull' technology for stemborer and Striga control in smallholder farming systems in western Kenya. Crop Prot. 2008, 27, 1084-1097, doi:10.1016/j.cropro.2008.01.005.

23. Khan, Z. R.; Midega, C. A. O.; Pittchar, J. O.; Murage, A. W.; Birkett, M. A.; Bruce, T. J. A.; Pickett, J. A. Achieving food security for one million sub-Saharan African poor through push-pull innovation by 2020. Philos. Trans. R. Soc. B Biol. Sci. 2014, 369, 20120284, doi:10.1098/rstb.2012.0284.

24. Khan, Z. R.; Midega, C. A. O.; Pittchar, J. O.; Murage, A. W.; Birkett, M. A.; Bruce, T. J. A.; 
Pickett, J. A. Achieving food security for one million sub-Saharan African poor through push-pull innovation by 2020. Philos. Trans. R. Soc. B Biol. Sci. 2014, 369, 20120284.

25. Siarta, S.; Blochb, R.; Knierima, A.; Bachingerb, J. Development of Agricultural Innovations in Organic Agriculture to adapt to Climate Change-Results from a Transdisciplinary R\&D Project in North-eastern Germany. In Producing and reproducing farming systems. New modes of organisation for sustainable food systems of tomorrow. 10th European IFSA Symposium, Aarhus, Denmark, 1-4 July 2012.; International Farming Systems Association, 2012.

26. Lang, D. J.; Wiek, A.; Bergmann, M.; Stauffacher, M.; Martens, P.; Moll, P.; Swilling, M.; Thomas, C. J. Transdisciplinary research in sustainability science: practice, principles, and challenges. Sustain. Sci. 2012, 7, 25-43, doi:10.1007/s11625-011-0149-x.

27. Allen, W.; Ogilvie, S.; Blackie, H.; Smith, D.; Sam, S.; Doherty, J.; McKenzie, D.; Ataria, J.; Shapiro, L.; MacKay, J.; Murphy, E.; Jacobson, C.; Eason, C. Bridging Disciplines, Knowledge Systems and Cultures in Pest Management. Environ. Manage. 2014, 53, 429 440, doi:10.1007/s00267-013-0180-z.

28. Mollinga, P. P. Zef - Interdisciplinary Course. 2002, 1997.

29. Hornidge, A.-K.; Ul Hassan, M.; Mollinga, P. P. Transdisciplinary innovation research in Uzbekistan - one year of 'Follow-the-Innovation.' Dev. Pract. 2011, 21, 834-847, doi:10.1080/09614524.2011.582085.

30. Stellmacher, T.; Grote, U. Forest coffee certification in Ethiopia: Economic boon or ecological bane?; ZEF working paper series, 2011;

31. Belay, D.; Foster, J. E. Efficacies of habitat management techniques in managing maize stem borers in Ethiopia. Crop Prot. 2010, 29, 422-428, doi:10.1016/j.cropro.2009.09.006.

32. Hurni, H. Agroecological Belts of Ethiopia. 1998, 43.

33. Spielman, D. J. Innovation systems perspectives on developing-country agriculture: A critical review; International food policy research institute (IFPRI). International service for national agricultural research (ISNAR) division, 2005;

34. Freeman, R. E. The Economic Institutions of Capitalism. Acad. Manag. Rev. 1987, 12, 385387, doi:10.5465/AMR.1987.4308003.

35. Oswald, A.; Miko, S.; Berthe, A. Sasakawa Africa Associa-on - - - Sasakawa Global 2000 Effective extension service delivery influences policy decisions and direct. 2000.

36. Rogers, E. M. C. N.-H. . R. 1983 Diffusion of innovations; 3rd ed.; Free Press ; Collier Macmillan: New York: London, 1983; ISBN 978-0-02-926650-2. 
37. Khan, Z. R.; Amudavi, D. M.; Midega, C. A. O.; Wanyama, J. M.; Pickett, J. A. Farmers' perceptions of a 'push-pull' technology for control of cereal stemborers and Striga weed in western Kenya. Crop Prot. 2008, 27, 976-987, doi:10.1016/j.cropro.2007.12.001.

38. Turner, R. Diffusion of Innovations, 5th edition, Everett M. Rogers. Free Press, New York, NY (2003), 551 pages; 2007; Vol. 14;.

39. Hornidge, A.-K.; Ul Hassan, M.; Mollinga, P. P. 'Follow the Innovation '-a Joint Experimentation \& Learning Approach to Transdisciplinary Innovation Research. AnnaKatharina Hornidge, Mehmood Ul-Hassan Peter P. Mollinga,'Follow Innov. '-A Jt. Exp. Learn. Approach to Transdiscipl. Innov. Res. 2009.

40. MOFED The Federal Democratic Republic of Ethiopia : Poverty Reduction Strategy Paper Annual Progress Report (2002/03). 2003, 156.

41. Caraça, J.; Lundvall, B.-Å.; Mendonça, S. The changing role of science in the innovation process: From Queen to Cinderella? Technol. Forecast. Soc. Change 2009, 76, 861-867, doi:10.1016/j.techfore.2008.08.003.

42. Amudavi, D. M.; Khan, Z. R.; Wanyama, J. M.; Midega, C. A. O.; Pittchar, J.; Nyangau, I. M.; Hassanali, A.; Pickett, J. A. Assessment of technical efficiency of farmer teachers in the uptake and dissemination of push-pull technology in Western Kenya. Crop Prot. 2009, 28, 987-996, doi:10.1016/j.cropro.2009.04.010.

43. Amudavi, D. M.; Khan, Z. R.; Wanyama, J. M.; Midega, C. A. O.; Pittchar, J.; Hassanali, A.; Pickett, J. A. Evaluation of farmers' field days as a dissemination tool for push-pull technology in Western Kenya. Crop Prot. 2009, 28, 225-235, doi:10.1016/j.cropro.2008.10.008.

44. Berhanu, K.; Poulton, C. The political economy of agricultural extension policy in Ethiopia: economic growth and political control. Dev. Policy Rev. 2014, 32, s197-s213.

45. Abate, T.; Shiferaw, B.; Gebeyehu, S.; Amsalu, B.; Negash, K.; Assefa, K.; Eshete, M.; Aliye, S.; Hagmann, J. A systems and partnership approach to agricultural research for development: Lessons from Ethiopia. Outlook Agric. 2011, 40, 213-220, doi:10.5367/oa.2011.0048.

46. Sayer, J.; Cassman, K. G. Agricultural innovation to protect the environment. Proc. Natl. Acad. Sci. 2013, 110, 8345-8348, doi:10.1073/pnas.1208054110.

47. Davis, K.; Ekboir, J.; Mekasha, W.; Ochieng, C. M. O.; Spielman, D. J.; Zerfu, E. Strengthening Agricultural Education and Training in Sub-Saharan Africa from an Innovation Systems Perspective. Ifpri 2007.

48. Belay, K. Agricultural extension in Ethiopia: the case of participatory demonstration and training extension system. J. Soc. Dev. Afr. 2003, 18, 49-84. 
49. McLean, L. D. A review and critique of Nonaka and Takeuchi's theory of organizational knowledge creation. In; 2004. 